\title{
The whole-genome sequencing in predicting Mycobacterium tuberculosis drug susceptibility and resistance in Papua, Indonesia
}

Yustinus Maladan ${ }^{1 *}$, Hana Krismawati', Tri Wahyuni', Ratna Tanjung ${ }^{1}$, Kamla Awaludin², Kholis Abdurachim Audah ${ }^{3}$ and Arli Aditya Parikesit ${ }^{4 *}$

\begin{abstract}
Background: Tuberculosis is one of the deadliest disease caused by Mycobacterium tuberculosis. Its treatment still becomes a burden for many countries including Indonesia. Drug resistance is one of the problems in TB treatment. However, a development in the molecular field through Whole-genome sequencing (WGS) can be used as a solution in detecting mutations associated with TB- drugs. This investigation intended to implement this data for supporting the scientific community in deeply understanding any TB epidemiology and evolution in Papua along with detecting any mutations in genes associated with TB-Drugs.
\end{abstract}

Result: A whole-genome sequencing was performed on the random samples from TB Referral Laboratory in Papua utilizing MiSeq 600 cycle Reagent Kit (V3). Furthermore, TBProfiler was used for genome analysis, RAST Server was employed for annotation, while Gview server was applied for BLAST genome mapping and a Microscope server was implemented for Regions of Genomic Plasticity (RGP). The largest genome of M. tuberculosis obtained was at the size of 4,396,040 bp with subsystems number at 309 and the number of coding sequences at 4326. One sample (TB751) contained one RGP. The drug resistance analysis revealed that several mutations associated with TB-drug resistance existed. In details, mutations of rpoB gene which were identified as S450L, D435Y, H445Y, L430P, and Q432K had caused the reduced effectiveness of rifampicin; while the mutases in katG (S315T), kasA (312S), inhA (I21V), and Rv1482c-fabG1 (C-15 T) genes had contributed to the resistance in isoniazid. In streptomycin, the resistance was triggered by the mutations in rpsL (K43R) and rrs (A514C, A514T) genes, and, in Amikacin, its resistance was led by mutations in rrs (A514C) gene. Additionally, in Ethambutol and Pyrazinamide, their reduced effectiveness was provoked by embB gene mutases (M306L, M306V, D1024N) and pncA (W119R).

Conclusions: The results from whole-genome sequencing of TB clinical sample in Papua, Indonesia could contribute to the surveillance of TB-drug resistance. In the drug resistance profile, there were 15 Multi Drugs Resistance (MDR) samples. However, Extensively Drug-resistant (XDR) samples have not been found, but samples were resistant to only Amikacin, a second-line drug.

\footnotetext{
* Correspondence: yustinus.maladan@litbang.kemkes.go.id;

arli.parikesit@i3l.ac.id

${ }^{1}$ Center for Papua Health Research and Development, Papua, Indonesia

${ }^{4}$ Department of Bioinformatics, School of Life Sciences, International Institute for Life Sciences (IBL), Jakarta, Indonesia

Full list of author information is available at the end of the article
}

(c) The Author(s). 2021 Open Access This article is licensed under a Creative Commons Attribution 4.0 International License, which permits use, sharing, adaptation, distribution and reproduction in any medium or format, as long as you give appropriate credit to the original author(s) and the source, provide a link to the Creative Commons licence, and indicate if changes were made. The images or other third party material in this article are included in the article's Creative Commons licence, unless indicated otherwise in a credit line to the material. If material is not included in the article's Creative Commons licence and your intended use is not permitted by statutory regulation or exceeds the permitted use, you will need to obtain permission directly from the copyright holder. To view a copy of this licence, visit http://creativecommons.org/licenses/by/4.0/ The Creative Commons Public Domain Dedication waiver (http://creativecommons.org/publicdomain/zero/1.0/) applies to the data made available in this article, unless otherwise stated in a credit line to the data. 


\section{Background}

Many innovations in tuberculosis (TB), as one of the top killer infectious diseases in many countries, were performed in diagnostic, transmission, drug resistance, drug therapy, prevention, and control programs. Indonesia is one of eight countries that accounts for two-thirds of the world's total TB cases, with a percentage of $8.5 \%$ [1]. Drug-resistant TB is a problem that needs extra attention when controlling tuberculosis [2]. Testing for susceptibility and resistance to anti-TB drugs can be carried out conventionally with the culture method. However, this method is less effective because of its timeconsuming. Thus, a faster method is needed, such as a molecular approach [1].

Next-generation sequencing (NGS) is a powerful tool for improving the management and control of tuberculosis $[3,4]$. Whole-genome sequencing (WGS) data from NGS can be used to quickly and accurately detect mutations associated with anti-TB drug resistance in clinical specimens [3].

The first complete TB genome was published in 1998 from the H37Rv strain [5]. After that, an advanced biomedical research was performed to complete many gaps of this slow-growing bacteria. Using NGS technologies, performing WGS in TB seems applicable to a wide range of clinical scenarios, even nationally. The whole bacterial genome sequencing can provide comprehensive data such as drug susceptibility and resistance prediction, epidemiological analysis, and research [6-8]. In addition, the existence of the WGS dataset allows researchers to assess genetic diversity across the genome looking for markers of selective stress. Selection can be measured by associating the ratio of nonsynonymous genetic change to synonymous change $(\mathrm{dN} / \mathrm{dS})$, in which a $\mathrm{dN} / \mathrm{dS}$ is more remarkable than others will be considered to reflect positive selection for the increased diversity [4].

WGS technologies allow the generation of the drug susceptibility in about 8-9 days, while conventional drug susceptibility tests need more than 14 days to perform the result. This technology becomes a valuable tool for monitoring antibiotic resistance which lead to the optimization of field intervention to prevent the broader spread of TB drug resistance. WGS can be carried out directly from the clinical samples because the online tools are available for data interpretation. Thus, the WGS data can be used for epidemiological analysis and research purposes $[6,8]$. University Medical Center Groningen (UMCG) had implemented these technologies for the outbreak management, pathogen characterization, and surveillance, as well as the rapid identification of bacteria using the $16 \mathrm{~S}-23 \mathrm{~S}$ rRNA region, taxonomy, metagenomic approaches to clinical samples, and the determination of the zoonotic microorganisms transmission from animals to humans [9].
Besides the technology to execute the WGS on TB, the development of many bioinformatics tools also enhances the increasing use of WGS, especially in data analysis. Recently, some approaches to interpret the results from the NGS machine have availed.

Comprehensive and robust open-source packages for the standardized NGS analysis also has appeared, such as UGENE [10]. There is many tools existed for genome analysis of WGS result. Some are available online such as Microscope for microbial comparative genome analysis and manual functional annotation [11]. The Microscope has the data-exploring features with many beneficial functionalities, such as allowing the users to perform (complex) queries, comparative genomics studies, and metabolic analyzes. It also provides the summary views of statistics and information for each genome as a whole. Usually, a complete Rapid Annotation using Subsystems Technology (RAST) was added for the same function. RAST is a fully automated service for annotating the complete or nearly complete bacterial and archaeal genomes. It gives high-quality genome annotations for these genomes across the whole phylogenetic tree $[12,13]$. For drug resistance analysis, the webserver of TB-Profiler allows users to analyze $M$. tuberculosis WGS data to predict its lineage and drug resistance $[14,15]$.

Currently, TB Control has become one of the national priorities of health development in Indonesia. Although Indonesia has made remarkable progress over the last decades, this disease remains becoming one of the country's top four causes of death. The easternmost part of Indonesia, especially Papua, was the most significant TB contributor in Indonesia lacking of studied data due to its geographical challenges. This paper presented WGS results from the clinical samples of pulmonary $\mathrm{TB}$ in $\mathrm{Pa}$ pua with the intention to contribute this data in supporting the scientific community to profoundly understand the epidemiology and evolution of TB in Papua.

\section{Results}

A total of 20 samples were sequenced, only 19 samples had good data quality. WGS was utilized in genotyping 19 samples of $M$. tuberculosis. The results of NGS reading compared to M. tuberculosis $\mathrm{H} 37 \mathrm{Rv}$ as a reference strain are displayed in Table 1.

Data analysis results exhibited that the biggest genome of $M$. tuberculosis in Papua strain was $4,396,040 \mathrm{bp}$ and the smallest was $4,354,210 \mathrm{bp}$. The genome size for H37Rv was 4,411,532 base pairs (bp) with $\mathrm{G}+\mathrm{C} 65.6 \%$ [5]. The standard deviation (SD) obtained was 12,685.32 which indicated a significant difference in the sample genome size is less than 10\% (Fig. 1). 
Table 1 Comparison between H37Rv and M. tuberculosis TB751 genomes from Papua

\begin{tabular}{lll}
\hline Genome & $\begin{array}{l}\text { M. tuberculosis TB751 from } \\
\text { Papua }\end{array}$ & $\begin{array}{l}\text { H37Rv } \\
\text { (Reference) }\end{array}$ \\
\hline Genome size & $4,396,040$ & $4,411,532$ \\
Number of subsystems & 309 & 389 \\
$\begin{array}{l}\text { Number of coding } \\
\text { sequences }\end{array}$ & 4326 & 3928 \\
Number of RNAs & 47 & 60 \\
\hline
\end{tabular}

The subsystem distribution of $M$. tuberculosis Papua strains was analyzed using the RAST server and visualized with the SEED server. RAST server identified protein-encoding, rRNA, and tRNA genes; assigned functions to the genes, and predicted which subsystems were represented in the genome. The genome that had been annotated by RAST server can be browsed in the comparative environment of SEED-Viewer. SEED served to provide consistent and accurate genome annotations based on the integration of genome data from genome databases, web front end, API, and server scripts [12, 13]. The sample used was TB751 because it had a larger genome size than the other samples. Largest genome selection was intended to minimize the existed gaps in the genome. The functional classification exhibited that amino acids and derivatives had a larger percentage in M. tuberculosis subsystem (290). In addition to amino acids and their derivatives, carbohydrates, cofactors, vitamins, fatty acids, and lipids also possessed a large percentage of the subsystem (Fig. 2). Most of the genes involved in amino acid biosynthesis were highly conserved in all Mycobacterium species [16]. This proved that amino acids had an essential function for pathogens including $M$. tuberculosis [17].

The number of subsystems in $M$. tuberculosis TB751 from Papua was 309 which was 80 points different compared to H37Rv. Meanwhile, compared to the number of

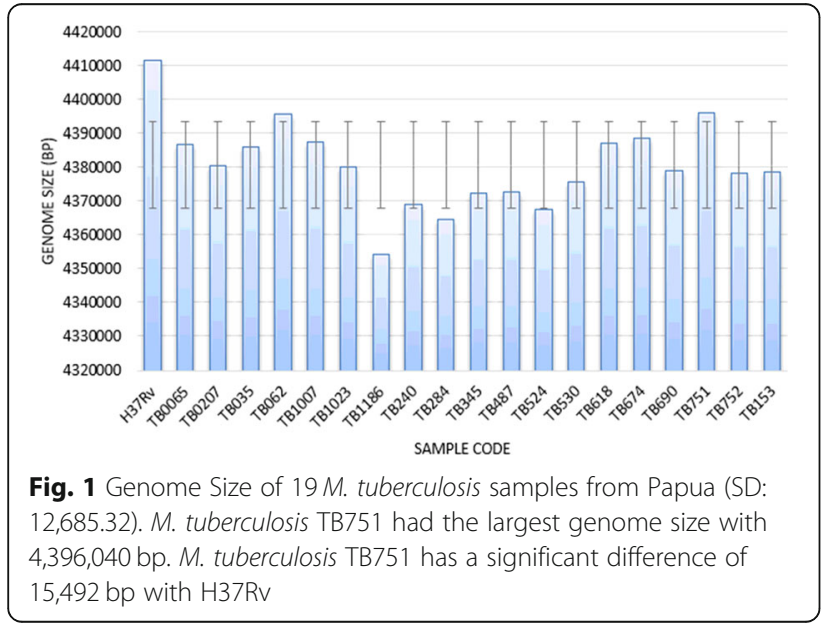

coding sequences with H37Rv, it was 398 point different. Meanwhile, the gap number of RNAs was 13 (Table 1). M. tuberculosis with Papua strain has a $\mathrm{G}+\mathrm{C}$ content at $65.6 \%$. These discrepancies could be feasible due to the difference in the annotation coverage strategies and in the instrument utilization.

The BLAST Atlas of M. tuberculosis Papua strain was created using the Gview server [18]. BLAST atlas was utilized to compare the genome of $M$. tuberculosis TB751 from Papua with H37Rv. M. tuberculosis TB751 from Papua was different with $\mathrm{H} 37 \mathrm{Rv}$ at $15,492 \mathrm{bp}$. However, CDS of M. tuberculosis TB751 had an almost similar distribution as the H37Rv genome (Fig. 3).

According to the Microscope server analysis, TB751 has an average CDS length of $929.12 \mathrm{bp}$, average intergenic length at 12124 , protein coding density at $91.32 \%$, and nosferatu repeated regions at $8.63 \%$. TB751 contained 8 pseudogenes. The genomic information of TB751 consists of 4483 genomics objects, 45 tRNAs, 3 RNAs, 36 misc_RNAs, 1 tmRNA, 0 ncRNA. Meanwhile, ribosomal RNA consists of, 1 ribosomal RNA 16S rRNA, 1 RNA 23S_rRNA and 1 RNA 5S_rRNA. The genomics information of TB751 is presented in a circular model using CGview [19] (Fig. 4).

The comparison of the genome of $M$. tuberculosis TB 751 and $M$. tuberculosis $\mathrm{H} 37 \mathrm{Rv}$ was carried out by employing a Microscope Server [11]. The RGF Finder on Microscope servers was able to search for any potential horizontally transferred genes (HGT) which were gathered in the genomic regions (Region of Genomic Plasticity). A region is considered RGP if a break must span at least $5 \mathrm{~kb}$ and must not contain more than 2 genes in the synteny. After that, the algorithm scans RGP for any HGT features (tRNA hotspot and/or mobility genes). Alien Hunter [20] which is an Interpolated Variable Order Motif (IVOM) has similar function as ScoreBased Identification of Genomic Islands-Hidden Markov Models (SIGI-HMM) [21] to capture other kinds of signals of the query sequence. A microscope incorporated with an IVOM or a SIGI-HMM will predict the overlapping regions but not the ones overlapped with RGP. In fact, M. tuberculosis TB751 contained an RGP. In the RGP of $M$. tuberculosis TB751, there were no overlapping regions based on the examination with SIGI and IVOM. RGP of $M$. tuberculosis 751 revealed that two regions did not exist in $M$. tuberculosis H37Rv. Both regions, in fact, were of a miscellaneous RNA (miscRNA) type (Table 2).

Miscellaneous RNA is shown in the middle part of the genome map (Fig. 5). The locus coordinate of the genome annotations in TB751_v1_miscRNA23 began at 2,294,031 and ended at 2,294,108, while for TB751_v1_ miscRNA24, it began at 2,300,100 and ended at $2,294,108$. Genome Browser interface visualized and 


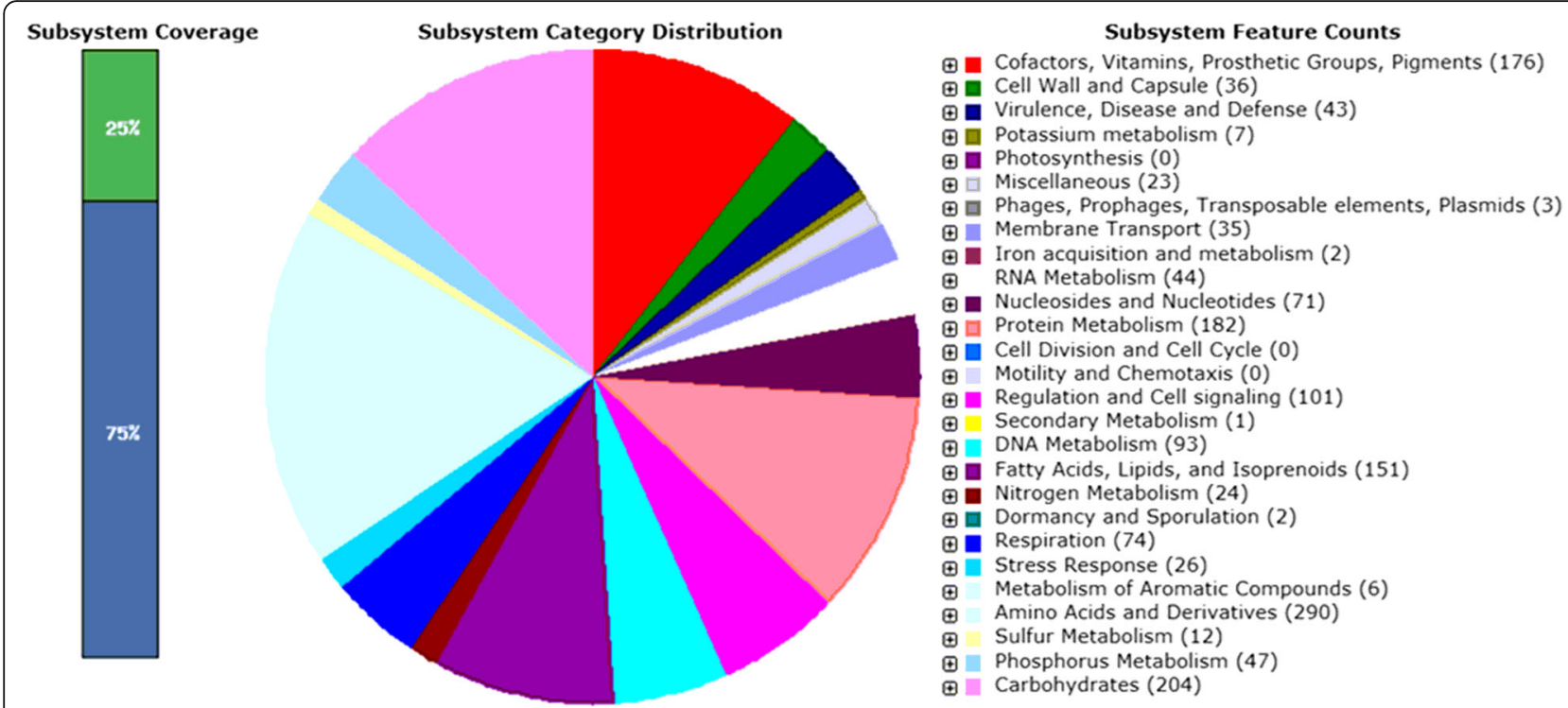

Fig. 2 Subsystem distribution of M. tuberculosis Papua strain (based on RAST annotation server). In subsystem coverage, $25 \%$ is indicated in subsystem and $75 \%$ is not in the subsystem. The most genome ontology subsystems are amino acids and derivatives which are accounted for 290

explored a replicon content (cartographic map of the genome) along with the similarity results (synteny maps) obtained and other bacterial genomes available in this study's PkGDB database Microscope or the complete proteome downloaded from the RefSeq /WGS sections. The synteny maps were calculated for all pairs of genomes from the PkGDB database (first synteny map) or the NCBI databank (second map). They represented the distribution of homologs of the current genome in other genomes from these databases. Each row on the map corresponded to one genome replicon (chromosome or plasmid) whose name is indicated on the left. The homologous gene in the regions between 2,294,031-2,300,177 was the region that encoded the polyketide synthase. Based on the PkGDB data, the area was homologous to M. tuberculosis Beijing strain, M. tuberculosis CDC1551, M. tuberculosis H37Ra, M. tuberculosis H37Rv PRJNA224116, M. tuberculosis HN878, M. tuberculosis

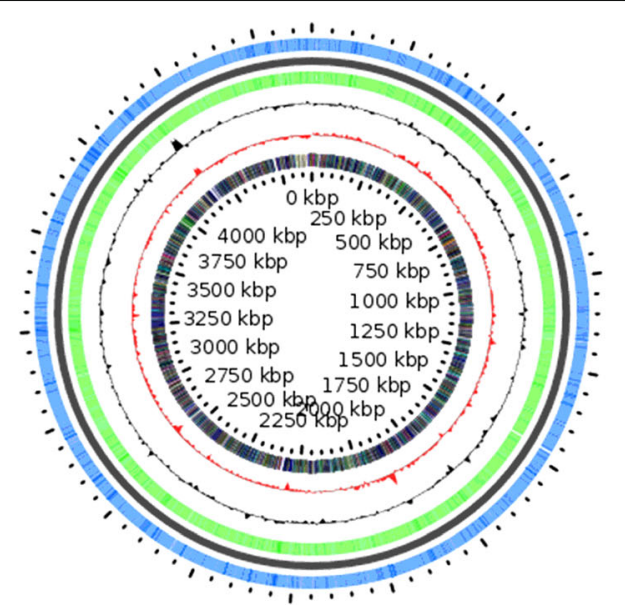

\begin{tabular}{|l|} 
M._tuberculosis_H37Rv.fasta \\
M._tuberculosis_from_Papua.gbk \\
GC content \\
GC skew
\end{tabular}

Fig. 3 The BLAST Atlas of M. tuberculosis TB751 Papua strain. BLAST was performed to the coding sequences (CDS) regions in the reference genome against CDS regions in the query genomes and its top hits were rendered in a genome map using GView. The inner-most slot on the map (black) shows CDS regions on the reference genome. The two outer slots (green and blue) display regions of M. tuberculosis H37Rv (blue) and M. tuberculosis from Papua (green) 


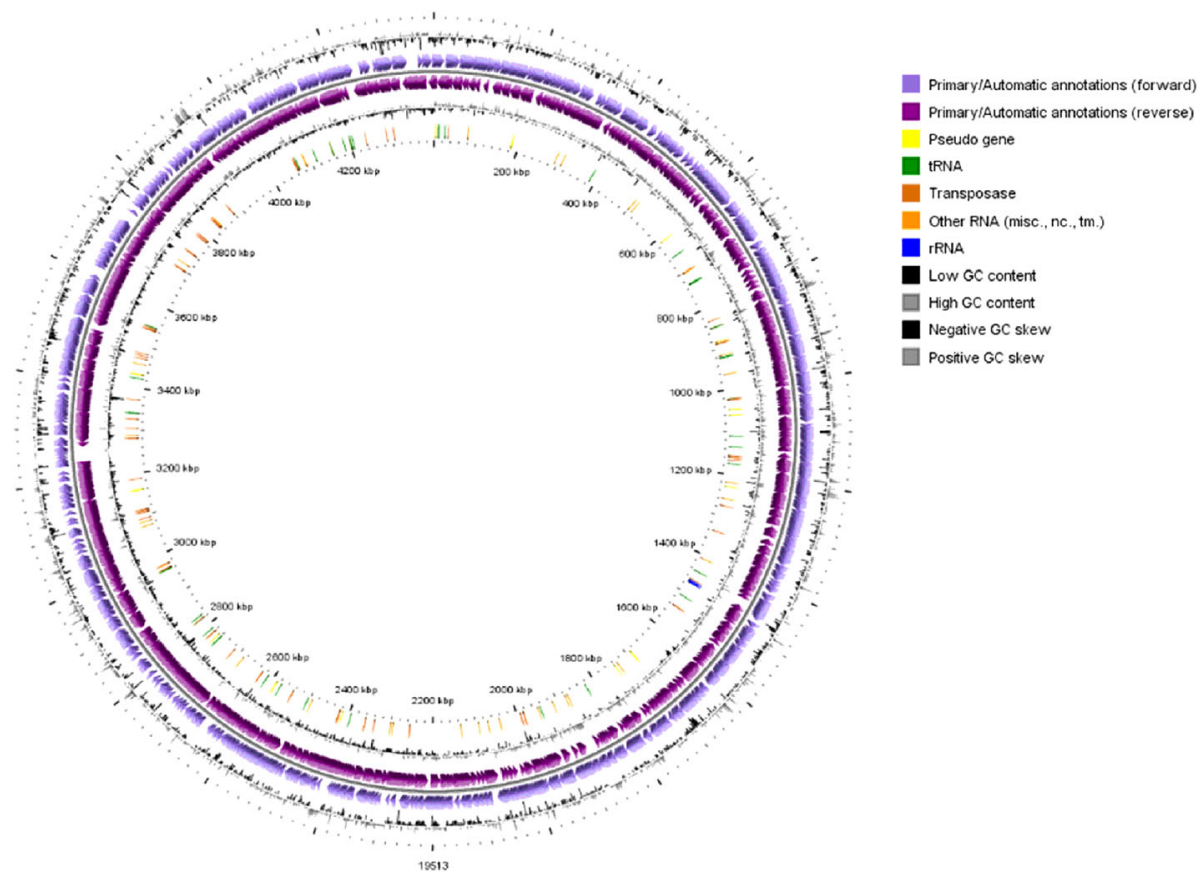

Fig. 4 Genome information of M. tuberculosis TB751. Circles display (from the outside): 1. Gene GC percentage deviation (gene GC\% - genome mean GC\%), 2. Predicted CDSs transcribed in the clockwise direction (violet), 3. Predicted CDSs transcribed in the counterclockwise direction (purple), 4. Gene GC skew (G-C/G +C), 5. rRNA (blue), tRNA (green), misc. RNA (orange), transposable elements (brown) and pseudogenes (yellow)

Table 2 Comparison of Regions of Genomic Plasticity in M. tuberculosis Papua strain and M. tuberculosis H37Rv using RGP Finder. Green: similar gene in the compared genome above cut-off value. Red: no similarity above the identity cut-off value. Red with 'no corresponding' text: no similarity at all.

\begin{tabular}{|c|c|c|c|c|c|c|c|c|c|}
\hline No & Label & Begin & End & Type & Product & Gene & SIGI & IVOM & $\begin{array}{c}\text { MYCTU_H } \\
\text { 37Rv }\end{array}$ \\
\hline $\mathbf{1}$ & TB751_v1_2305 & $2,283,920$ & $2,285,425$ & CDS & $\begin{array}{l}\text { Carboxylic ester } \\
\text { hydrolase }\end{array}$ & - & - & - & + \\
\hline 2 & $\begin{array}{l}\text { TB751_v1_2 } \\
306\end{array}$ & $2,285,504$ & $2,286,160$ & CDS & $\begin{array}{l}\text { putative lipoprotein } \\
\text { lppI }\end{array}$ & - & - & - & + \\
\hline 3 & TB751_v1_2307 & $2,286,197$ & $2,288,761$ & CDS & $\begin{array}{l}\text { Phosphoenolpyruv } \\
\text { ate synthase }\end{array}$ & - & - & - & + \\
\hline 4 & TB751_v1_2308 & $2,288,766$ & $2,301,221$ & CDS & $\begin{array}{l}\text { Narbonolide/10- } \\
\text { deoxymethynolide } \\
\text { synthase PikA2, } \\
\text { modules } 3 \text { and } 4\end{array}$ & pikAII & - & - & + \\
\hline 5 & $\begin{array}{l}\text { TB751_v1_miscR } \\
\text { NA23 }\end{array}$ & $2,294,031$ & $2,294,108$ & misc_RNA & ASpks & - & - & - & no corresp \\
\hline 6 & $\begin{array}{l}\text { TB751_v1_miscR } \\
\text { NA24 }\end{array}$ & $2,300,100$ & $2,300,177$ & misc_RNA & ASpks & - & - & - & no corresp \\
\hline 7 & TB751_v1_2309 & $2,301,528$ & $2,301,830$ & CDS & $\begin{array}{l}\text { conserved protein } \\
\text { of unknown } \\
\text { function }\end{array}$ & - & - & - & + \\
\hline 8 & TB751_v1_2310 & $2,302,056$ & $2,302,391$ & CDS & $\begin{array}{l}\text { RNA polymerase- } \\
\text { binding protein } \\
\text { RbpA }\end{array}$ & rbpA & - & - & + \\
\hline 9 & TB751_v1_2311 & $2,302,366$ & $2,305,155$ & CDS & $\begin{array}{l}\text { Apolipoprotein N- } \\
\text { acyltransferase / } \\
\text { Polyprenol } \\
\text { monophosphoman } \\
\text { nose synthase }\end{array}$ & $\ln t$ & - & - & + \\
\hline 10 & TB751_v1_2312 & $2,305,148$ & $2,306,752$ & CDS & $\begin{array}{l}\text { Exoenzymes } \\
\text { regulatory protein } \\
\text { aepA precursor }\end{array}$ & - & - & - & + \\
\hline
\end{tabular}




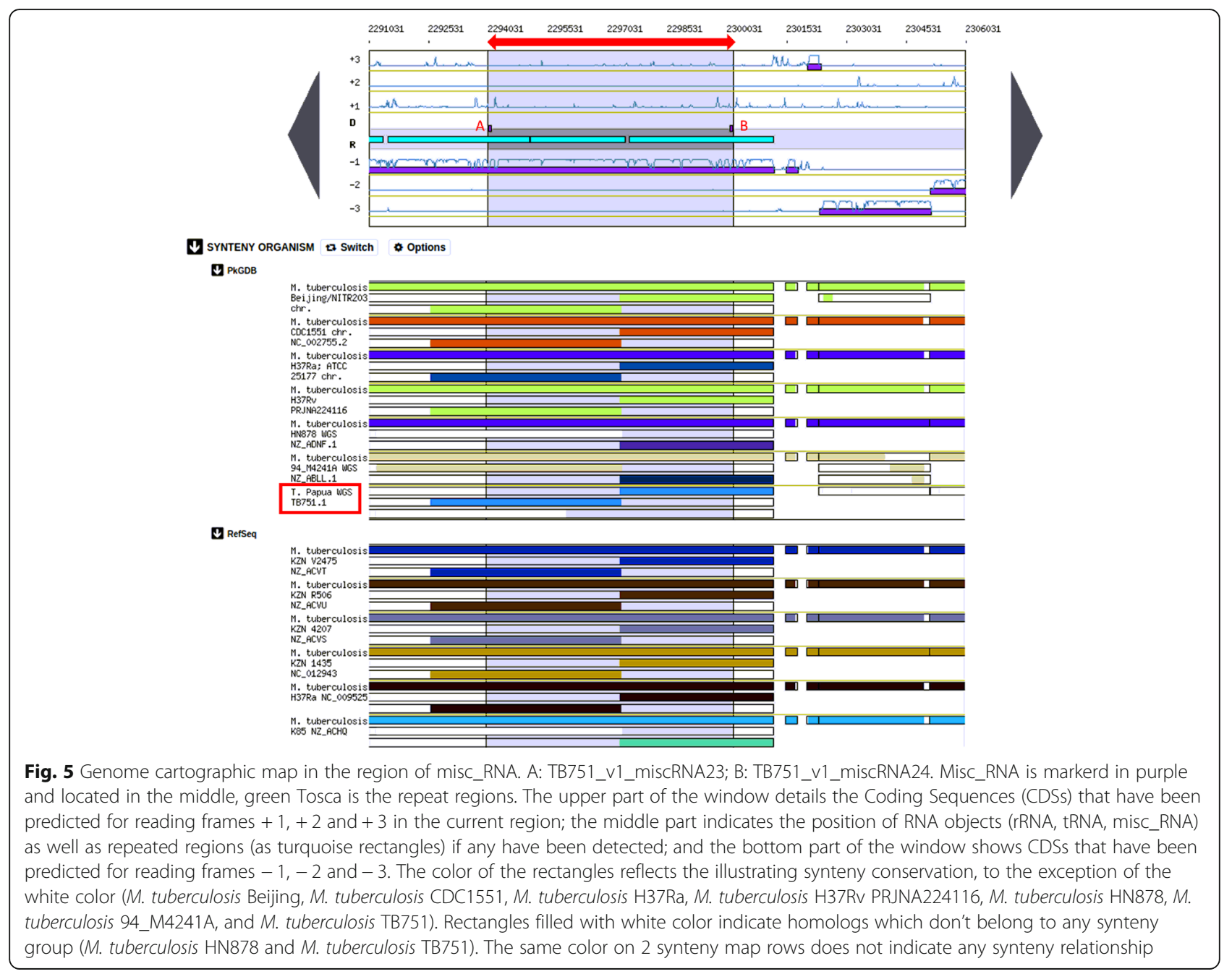

94_M4241A, and M. tuberculosis TB751 from Papua. In $\mathrm{PkGDB}$, the region bounded by the gray area was the CDS region that produced polyketide synthase (Fig. 5).

Furthermore, the identification of TB drug resistance both in the first line and in the second line could be done using TBProfiler (Table 3). TBProfiler had the sensitivity in detecting MDR-TB which was $94 \%$ with a specificity of $98 \%$. For XDR-TB, the sensitivity was $83 \%$ and its specificity was $96 \%$ [15]. Multidrug-resistant tuberculosis (MDR-TB) appears if M. tuberculosis does not respond to, at least, isoniazid and rifampin. Whereas Extensively drug-resistant TB (XDR-TB) is a form of MDR-TB which is also resistant to two groups of second-line anti-TB drugs [22]. A total of 15 samples obtained had MDR and no XDR was found. In regard to spoligotype family, 19 samples of $M$. tuberculosis from Papua consisted of three spoligotype families, namely East African-Indian (EAI), Latin AmericanMediterranean (LAM), and Beijing RD105.

First-line TB drugs consist of isoniazid, rifampicin, pyrazinamide, ethambutol, Streptomycin [23]. Based on mutation analysis using TBProfiler on 19 samples of $M$. tuberculosis from Papua, resistance was found to firstline TB drugs such as rifampicin, isoniazid, streptomycin, ethambutol, and pyrazinamide. As Therapeutic Target Database (TTD) database provides annotations on the drug-protein interactions, it also annotates the second-line drug related to the SNP as well (Table 4). Resistance to rifampicin is caused by mutations in the rpoB gene [25]. In M. tuberculosis sample from Papua, several mutases were found in $r p o B$ gene, namely S450L, D435Y, H445Y, L430P, Q432K (Table 4). These mutations have been confirmed to cause resistance to rifampicin [3, 26]'. In isoniazid, four genes were found containing mutations associated with isoniazid resistance, they were katG (S315T), kasA (G312S), inhA (I21V), and fabG1(C-15 T). Furthermore, TTD database also displayed that the protein of Bacterial Fatty acid synthetase I (Bact inhA) is the most common target for the first-line drug-related SNP as this is the most common finding in the wet laboratory. Resistance to streptomycin, ethambutol, and pyrazinamide was annotated 
Table 3 Resistance phenotype and genotype of matched pairs. Inh (isoniazid); Rif (rifampin); Emb (ethambutol); Str (streptomycin); Pza (pyrazinamide); Amk (amikacin)

\begin{tabular}{|c|c|c|c|c|c|c|c|c|c|}
\hline Sample Code & Xpert & Spoligo. Family & Inh & Rif & Emb & Str & Pza & Amk & Note \\
\hline TB0065 & $\mathrm{R}$ & EAI & $R$ & $R$ & $R$ & $R$ & & & MDR \\
\hline TB0207 & $\mathrm{R}$ & EAI & $\mathrm{R}$ & $\mathrm{R}$ & & & & & MDR \\
\hline TB035 & $R$ & EAI & $R$ & $R$ & $\mathrm{R}$ & $\mathrm{R}$ & & & MDR \\
\hline TB062 & R & EAl & $R$ & R & & & & & MDR \\
\hline TB1007 & $R$ & EAI & $R$ & $\mathrm{R}$ & & & & & MDR \\
\hline TB1023 & R & LAM & & R & & & & & - \\
\hline TB1186 & $\mathrm{R}$ & Beijing RD105 & $R$ & $\mathrm{R}$ & & & & & MDR \\
\hline TB240 & R & LAM & $R$ & & & & & & - \\
\hline TB284 & R & Beijing RD105 & R & R & $\mathrm{R}$ & & $\mathrm{R}$ & & MDR \\
\hline TB345 & $R$ & Beijing RD105 & $R$ & $R$ & & & & & MDR \\
\hline TB487 & $R$ & Beijing RD105 & $R$ & $\mathrm{R}$ & & & & & MDR \\
\hline TB524 & $R$ & Beijing RD105 & & $R$ & & & & & - \\
\hline TB530 & $\mathrm{R}$ & LAM & $\mathrm{R}$ & $\mathrm{R}$ & $\mathrm{R}$ & & & & MDR \\
\hline TB618 & $R$ & LAM & & & & $\mathrm{R}$ & & R & MDR \\
\hline TB674 & $\mathrm{R}$ & EAI & $\mathrm{R}$ & $\mathrm{R}$ & & & & & MDR \\
\hline TB690 & R & LAM & R & R & & & & & MDR \\
\hline TB751 & R & LAM & & & & $\mathrm{R}$ & & & - \\
\hline TB752 & R & LAM & $R$ & R & $\mathrm{R}$ & & & & MDR \\
\hline TB153 & $\mathrm{R}$ & EAI & $\mathrm{R}$ & $\mathrm{R}$ & & & & & MDR \\
\hline
\end{tabular}

Table 4 First-line and second-line drug-related SNPs identified using TBProfiler and TTD database search result of the drug functional annotations [24]

\begin{tabular}{|c|c|c|c|c|}
\hline Drug & Gene & SNP mutation & Protein Target & TTD Link \\
\hline \multicolumn{5}{|l|}{ First-line } \\
\hline Rifampicin & $r p o B$ & $\begin{array}{l}\text { S450L, D435Y, H445Y, L430P, } \\
\text { Q432K }\end{array}$ & $\begin{array}{l}\text { Bacterial RNA polymerase switch region } \\
\text { (Bact RNAP-SR) }\end{array}$ & $\begin{array}{l}\text { http://db.idrblab.net/ttd/data/drug/ } \\
\text { details/d0g3dl }\end{array}$ \\
\hline Isoniazid & katG & S315T & \multirow[t]{4}{*}{ Bacterial Fatty acid synthetase I (Bact inhA) } & \multirow{4}{*}{$\begin{array}{l}\text { http://db.idrblab.net/ttd/data/target/ } \\
\text { details/t79068 }\end{array}$} \\
\hline Isoniazid & kasA & G312S & & \\
\hline Isoniazid & $\operatorname{inh} A$ & $121 \mathrm{~V}$ & & \\
\hline Isoniazid & $\begin{array}{l}\text { Rv1482c- } \\
\text { fabG1 }\end{array}$ & $C-15 T$ & & \\
\hline Streptomycin & rpsL & K43R & $\begin{array}{l}\text { Staphylococcus } 30 \text { ribosomal subunit (Stap- } \\
\text { coc pbp2) }\end{array}$ & $\begin{array}{l}\text { http://db.idrblab.net/ttd/data/target/ } \\
\text { details/t72657 }\end{array}$ \\
\hline Streptomycin & rrs & A514C, A514T & $\begin{array}{l}\text { Mycobacterium Arabinosyltransferase } C \\
\text { (MycB embC) }\end{array}$ & $\begin{array}{l}\text { http://db.idrblab.net/ttd/data/target/ } \\
\text { details/t30578 }\end{array}$ \\
\hline Ethambutol & $e m b B$ & M306L, M306V, D1024N & $\begin{array}{l}\text { Mycobacterium Arabinosyltransferase } C \\
\text { (MycB embC) }\end{array}$ & $\begin{array}{l}\text { http://db.idrblab.net/ttd/data/target/ } \\
\text { details/t30578 }\end{array}$ \\
\hline Pyrazinamide & pncA & W119R & Bacterial Fatty acid synthetase I (Bact inhA) & $\begin{array}{l}\text { http://db.idrblab.net/ttd/data/target/ } \\
\text { details/t79068 }\end{array}$ \\
\hline \multicolumn{5}{|l|}{ Second-Line } \\
\hline Amikacin & rrs & A514C & $\begin{array}{l}\text { Staphylococcus } 30 \text { ribosomal subunit (Stap- } \\
\text { coc pbp2) }\end{array}$ & $\begin{array}{l}\text { http://db.idrblab.net/ttd/data/target/ } \\
\text { details/t72657 }\end{array}$ \\
\hline
\end{tabular}


respectively due to its mutations in the rpsL (K43R), rrs (A514C, A514T), embB (M306L, M306V, D1024N), and pncA (W119R) genes [25, 27].

Second-line injectable drugs include kanamycin, amikacin, and capreomycin [28, 29]. Mutations in rrs gene are the cause of resistance to amikacin [25, 27]. The mutation generated from $M$. tuberculosis from Papua was A514C (Table 4). The application of WGS test in all cases of TB can assist TB control efforts and increase the accuracy of prediction in molecular resistance leading to more effective patient management and drug resistance surveillance $[6,9,10]$. This information is important for doctors to make quick decisions about the best therapy in the treatment of MDR-TB/XDR-TB [3, 5].

\section{Discussions}

Since TB is one of diseases with highest burden in Papua Province of the Republic of Indonesia, thus, understanding the molecular epidemiology of M. tuberculosis Papua strain is very important. Sequencing technology, combined with bioinformatics and rapidly developing information technology, can be utilized in clinical fields such as public health microbiology [30]. Using NGS, WGS of M. tuberculosis can be completed faster, more affordable, and increasingly accessible as the alternative for molecular epidemiology studies. This database was supposed to contribute to the genetic polymorphism landscape of $M$. tuberculosis in Papua, especially the mutation that drives TB resistance. Moreover, genetic data will also enhance our understanding of strain distribution to see the crossborder transmission in borderline areas between two countries like Papua Province (Republic of Indonesia) and Papua New Guinea, especially in the area of Jayapura which is located in the borderline, and the interaction between people from Papua and Papua New Guinea are very intense. Therefore, this study assumed that the distribution of the strain is closely related to each other.

WGS on 19 samples of $M$. tuberculosis resulted in the locus coordinate of 4,354,210-4,396,040 bp; which was 99.6\% similar to the first whole-genome sequence by Cole [5]. Cole revealed 4000 genes with very high guanine + cytosine content [5]. This size was slightly larger compared to M. tuberculosis PR08 from Malaysia. The size of the genome of $M$. tuberculosis PR08 was $4,292,364$ bp with a $G+C$ content of $65.2 \%$ [31]. Similarly, the genome of $M$. tuberculosis $\mathrm{K}$ strain from Korea had a size of $4,385,518 \mathrm{bp}$ with a $\mathrm{G}+\mathrm{C}$ content of 65.59\%, 4194 CDSs, and 45 tRNAs, and one rRNA operon [32]. Meanwhile, TB751 from Papua had 25\% in the subsystem consisting of 1080 CDS (987 nonhypothetical, 93 hypothetical) and $75 \%$ was not in the subsystem comprised with 3246 CDS (2177 nonhypothetical, 1069 hypothetical). Papua strain genomes were composed with 309 subsystems including 43 subsystems of virulence, disease, and defends. Besides carbohydrates and amino acids, Fatty Acids, lipids, and Isoprenoids dominated the subsystem (Fig. 1).

Furthermore, the most dominant CDS in the subsystem is amino acids and derivatives (26.85\%), Carbohydrates (18.8\%), Protein metabolism (16.86\%), and cofactors, vitamins, prosthetics groups, and pigments (16.29\%) (Fig. 1). In the non-tuberculous mycobacteria, the subsystem classification suggested that $18 \%$ of the gene ontologies belong to amino acids and its derivatives category, $12 \%$ to Cofactors, vitamins, prosthetic groups and pigments [33]. The biosynthesis of amino acids and their derivatives greatly determines the survival of bacteria. This function is controlled by the subsystems in the category of amino acids and their derivatives. Correspondingly, shikimate biosynthetic pathway is one of the controlled systems of this subsystem in which 3deoxy-D-arabino- heptulosonate-7-phosphate (DAHP) will be converted into chorismite, which is useful in the synthesis of all aromatic amino acids, as well as other important metabolites in bacteria [34]. Vitamin B6, one of the most central molecules in the cells of living organisms, is an essential cofactor in various biochemical reactions that regulate primary cellular metabolism affecting overall physiology [35].

Meanwhile, RGPs can be the sites of integrated Mobile Genetic Elements (MGEs) insertions or the particular segments removal result of DNA in one or more TB strains. In TB751, two types of misc_RNA were found, but not in $M$. tuberculosis H37Rv, which were TB751_ v1_miscRNA22 and TB751_v1_miscRNA23. Thus, the resulted product of the two regions is ASpks (Table 2). On the Mycobrowser server, Aspk is considered as a gene which produces putative small regulatory RNA whose function is still unknown.

Drug resistance profiling with WGS is very beneficial in detecting the specific mutations as well as in the correct interpretation to predict drug resistance or susceptibility [36].

Quality sequence data can be used to determine accurately the existing mutations associated with first-line and second-line drug resistance [2]. From the whole genome of $M$. tuberculosis, this investigation identified the mutations in genes associated with drug resistance in $M$. tuberculosis using TBProfiler [15]. TBProfiler gave 100\% concordance with phenotypic DST results for INH, RIF, STR, ETB, ETH, and the fluoroquinolones [37]. In the case of resistance, this study analyzed 19 samples, 15 of which were MDR, and no sample was XDR [38]. However, the awareness of XDR should be improved because a Papuan strain resistant to amikacin (sample 618) had existed. The analysis revealed that MDR TB cases in Papua need to be monitored for the effectiveness of 
tuberculosis treatment. Overall, the analyzed samples displayed resistance to rifampicin, isoniazid, Ethambutol, streptomycin, pyrazinamide, and amikacinin (Table 3).

The mutations in $r p o B$ gene has led the resistance to rifampin. Mutations at positions D435Y/V (D516Y/V), H445Y/D (H526Y/D), and S450L (S531L) (parentheses using $E$. coli residue numbering) have constituted the majority of mutations within this region [3, 39]. In the Papua strain, the mutations that were found were S450L, D435Y, H445Y, L430P, Q432K (Table 4). These mutations have been confirmed as the cause of resistance to rifampin through in vitro methods $[27,40]$. Mutations in $k a t G, k a s A$, inhA, and $f a b G 1$ genes caused resistance to isoniazid. They encode Catalase-peroxidaseperoxynitritase $\mathrm{T}$ katG, beta-ketoacyl-ACP synthase, NADH- dependent enoyl-ACP reductase 3-Oxoacyl[acyl-carrier-protein] reductase, and oxoacyl- [acyl-carrier protein] reductase fabG1. Genes mutation in that region has triggered $M$. tuberculosis resistant to isoniazid [41, 42]. Mutations in $k a t G, k a s A, \operatorname{inh} A$, and fabG1 genes have provoked resistance to isoniazid. They encode Catalase-peroxidase-peroxynitritase $\mathrm{T}$ katG, betaketoacyl-ACP synthase, NADH- dependent enoyl-ACP reductase 3-Oxoacyl-[acyl-carrier-protein] reductase, and oxoacyl- [acyl-carrier protein] reductase fabG1. Genes mutation in that region have initiated $M$. tuberculosis resistant to isoniazid [43]. Meanwhile, any resistance to streptomycin can be induced by the mutases in rpsL (K43R) and rrs A514C, A514T genes [36]. In addition, any resistance to Ethambutol can occur when mutations appear in $e m b B$ genes such as M306L, M306V, and D1024N occur [36]. Lastly, any resistance in pyrazinamide has occurred when there is a mutase in pncA gene, such as W119R [44].

Three lineages of $M$. tuberculosis strains of Papua were LAM, EAI, and Beijing. Beijing strain was reported as the responsible strain of MDR TB. In many areas of Asia, the Beijing strain was also reported in some cases to be the cause of TB outbreaks. Papua New Guinea reported Beijing strain and Euro-America as the lineage in Torres Strait that was riskily transported to Australia. In another part of PNG, particularly in Daru Island, an emergency of MDR-Tb by Beijing sub-lineage was reported. Using phylogenetic analysis combining with detailed molecular dating, they reveal that Beijing strains have been in local distribution since 1940 and first acquired drug resistance in 1960.

The comparison of the study finding in Papua Province of Indonesia with the previous finding in PNG can be defined as a cross border distribution of MTB. It is quite reasonable since the citizens of Papua Province travel between two countries daily for trading and other activities. Furthermore, the populations of the two regions were anthropologically connected. The other two lineages of Papua strain indicated that they were not too widespread among Asian countries. East African Indian was reported in Myanmar beside Beijing. LAM was found in Uganda but not found in another part of Indonesia. Therefore, in this open-access era, genomic surveillance of MTB is a necessary action for monitoring the strain mutation, especially on drug target genes and pathogenic associated genes [45].

The limitation of this study was the lack of epidemiology data describing TB patients' characteristics because the samples were the unlinked specimens from the biobank of the provincial central laboratory. Moreover, the documentation of morphology and physiology of MTB was also minimal. However, this investigation had exposed the genetic data to define the potential surveillance approach of TD drugs resistance.

\section{Conclusion}

The improvement of the genomic surveillance for the MTB strains in Papua are very important to comprehend the molecular epidemiology of this disease. The WGS data obtained can be used in monitoring the development of gene mutations associated with anti-TB drug resistance in Papuan strains. From the WGS data, it is known that most of the samples were MDR and no XDR cases were found.

\section{Methods}

This investigation was a descriptive observational study using a molecular approach.

\section{Samples}

Samples were selected randomly from M. tuberculosis archives of Papua Province referral laboratory. The total sample obtained was $20 \mathrm{M}$. tuberculosis from clinical sputum samples of non-HIV pulmonary TB patients. The diagnostic steps of TB clinical samples were carried out according to TB diagnostic standards using Indonesian national guidelines. The detection of $M$. tuberculosis was done by applying Ziehl Nielson.

Staining, MGIT test, and bacterial culture in Lowenstein Johnson medium. All specimens were checked by employing GeneX- pertMTB/RIF according to the Indonesian national guidelines.

\section{DNA extraction of $M$. tuberculosis}

Deoxyribonucleic Acid (DNA) was extracted from bacterial colony on LJ medium by applying Qiaamp DNA Mini Kit (cat.51304). The procedure of DNA extraction was followed by the manufacturing instructions with some modifications. Before following the manual, the bacterial cell was boiled at $55^{\circ} \mathrm{C}$ for $15 \mathrm{~min}$. Then, the purity of the extraction results was measured by a nanodrop spectrophotometer at a wavelength of 260/280. 


\section{Library preparation and sequencing}

The quantification of extracted $M$. tuberculosis DNA was measured by employing Qubit TM 3.0 (Thermo Fisher Scientific). Next-Generation Sequencing procedure was then followed by Nextera XT DNA Library Prep Kit [46]. This NGS process was carried out using the MiSeq 600 cycle Reagent Kit (V3). WGS of M. tuberculosis was completed with NGS by applying MiSeq (Illumina Corp.) through the tagging of $M$. tuberculosis genome with Nextera transposon. Then, the library amplification was performed using Nextera PCR Master Mix, while the purification of the amplification product was conducted by applying AMPure XP beads. After purification, Nextera XT DNA Library Preparation Kits were utilized to normalize the library. Pooling DNA was finalized on a single tube and dilution was run using the Bead-Based Normalization Method [47]. Ultimately, DNA was loaded on the cartridge and WGS was performed on MiSeq.

\section{Bioinformatics pipeline}

Genome analysis was performed by utilizing TBProfiler software https://github.com/jodyphelan/TBProfiler [14, 15] on Linux platform. Unipro Ugene NGS 1.3.1 (ugene net) was applied for BAM file analysis, visualization reading, consensus and alignment creation. $M$. tuberculosis genome was annotated using RAST Server (http:// rast.theseed.org/FIG/rast.cgi) [12, 13]. Meanwhile, BLAST genome mapping was conducted using Gview server [18]. Genome analysis was completed by employing a Microscope server, especially on the Regions of Genomic Plasticity [11]. Furthermore, mycobacterium gene function was analyzed by Mycobrowser [48].

\section{Supplementary Information}

The online version contains supplementary material available at https://doi. org/10.1186/s12864-021-08139-3.

Additional file 1.

\begin{abstract}
Acknowledgments
The authors would like to express their gratitude to the Head of the Jayapura Regional Health Laboratory. Authors also would like to thank the Head of Center for Papua Health Research and Development who has allowed the researchers to do the research activities in his laboratory along with providing supports and funding for this research. Lastly, the authors are grateful to Andamar Pradipta, M.A. from the i $3 \mathrm{~L}$ Community Language Center for his excellent proofreading of this manuscript.
\end{abstract}

\section{Authors' contributions}

YM and HK have had equal contribution in this article. YM and HK have designed the study, conducted WGS, analyzed the data, and written the manuscripts. TW and RT have performed a laboratory assay. KA have collected the samples. KAA and AAP have been the data curators and had also contribution in writing the manuscript. All authors have read and approved the manuscript.

\section{Funding}

Our gratitude goes to the Center for Papua Health Research and Development for providing us with supports and funding.

\section{Availability of data and materials}

The datasets used and/or analyzed during the current study are available from the corresponding author on reasonable request.

\section{Declarations}

\section{Ethics approval and consent to participate}

All study protocols were approved by National Institute of Health Research and Development $\mathrm{MoH}$ Indonesia ethics committee with the reference number of LB.02.01/5.2/KE 153. Signed informed consent was obtained from all patients. All methods were carried out in accordance with relevant guidelines and regulations.

\section{Consent for publication}

Not applicable.

\section{Competing interests}

We declare that there is no any competing interests.

\section{Author details}

${ }^{1}$ Center for Papua Health Research and Development, Papua, Indonesia. 2Jayapura Regional Health Laboratory, Papua, Indonesia. ${ }^{3}$ Department of Biomedical Engineering, Swiss German University, Tangerang, Indonesia.

${ }^{4}$ Department of Bioinformatics, School of Life Sciences, International Institute for Life Sciences (I3L), Jakarta, Indonesia.

Received: 18 June 2021 Accepted: 1 November 2021

Published online: 22 November 2021

\section{References}

1. WHO. Global Tuberculosis Report 2020 [Internet]. Geneva: WHO; 2020. 1232.

2. WHO. Global Leprosy Strategy 2016-2020: accelerating towards a leprosyfree world. Vol. 1, Weekly Epidemiological record. 2016. 349-360.

3. $\mathrm{WHO}$. The use of next-generation sequencing technologies for the detection of mutations associated with drug resistance in Mycobacterium tuberculosis complex: technical guide. Geneva; 2018. 15-128.

4. Ford C, Yusim K, loerger T, Feng S, Chase M, Greene M, et al. Mycobacterium tuberculosis e Heterogeneity revealed through whole genome sequencing. Tuberculosis. 2012;92(3):194-201. https://doi.org/10.1016/j.tube.2011.11.003.

5. Cole ST, Brosch R, Parkhill J, Garnier T, Churcher C, Harris D, et al. Deciphering the biology of Mycobacterium tuberculosis from the complete genome sequence. Nature. 1998;396(6685):537-44. https://doi.org/10.103 8/31159.

6. Satta G, Lipman M, Smith GP, Arnold C, Kon OM, McHugh TD. Mycobacterium tuberculosis and whole-genome sequencing: how close are we to unleashing its full potential? Clin Microbiol Infect 2017;24(6):604-609. https://doi.org/10.1016/j.cmi.2017.10.030, DOl: https://doi.org/10.1016/j. cmi.2017.10.030

7. Iketleng T, Lessells R, Dlamini MT, Mogashoa T, Mupfumi L, Moyo S, et al. Mycobacterium tuberculosis next-generation whole genome sequencing : opportunities and challenges. Tuberc Res Treat. 2018;2018:1-8. https://doi. org/10.1155/2018/1298542

8. Köser CU, Ellington MJ, Peacock SJ. Whole-genome sequencing to control antimicrobial resistance. Trends Genet. 2014;30(9):401-7. https://doi.org/10.1 016/j.tig.2014.07.003

9. Deurenberg RH, Bathoorn E, Chlebowicz MA, Couto N, Ferdous M, Garcíacobos S, et al. Application of next generation sequencing in clinical microbiology and infection prevention. J Biotechnol. 2017;243:16-24. https://doi.org/10.1016/j.jbiotec.2016.12.022

10. Okonechnikov K, Golosova O. Fursov M. Unipro UGENE : a unified bioinformatics toolkit. 2012;28(8):1166-7. https://doi.org/10.1093/bioinforma tics/bts091

11. Vallenet D, Calteau A, Cruveiller S, Gachet M, Lajus A, Josso A, et al. MicroScope in 2017: an expanding and evolving integrated resource for community expertise of microbial genomes. Nucleic Acids Res. 2017:45(D1): D517-28. https://doi.org/10.1093/nar/gkw1101. 
12. Aziz RK, Bartels D, Best AA, Dejongh M, Disz T, Edwards RA, et al. The RAST server: rapid annotations using subsystems technology. BMC Genomics. 2008;9(75):1-15. https://doi.org/10.1186/1471-2164-9-75.

13. Overbeek R, Olson R, Pusch GD, Olsen GJ, Davis JJ, Disz T, et al. The SEED and the rapid annotation of microbial genomes using subsystems technology (RAST). Nucleic Acids Res. 2014;42(D1):D206-14. https://doi.org/1 $0.1093 / \mathrm{nar} / \mathrm{gkt} 1226$.

14. Coll F, McNerney R, Preston MD, Guerra-Assunção JA, Warry A, HillCawthorne G, et al. Rapid determination of anti-tuberculosis drug resistance from whole-genome sequences. Genome med. 2015;7(1):1-10. Available from:

15. Phelan JE, O'Sullivan DM, Machado D, Ramos J, Oppong YEA, Campino S, O'Grady J, McNerney R, Hibberd ML, Viveiros M, Huggett JF, Clark TG Integrating informatics tools and portable sequencing technology for rapid detection of resistance to anti-tuberculous drugs. Genome Med. 2019;11(1): 1-7, 41, DOI: https://doi.org/10.1186/s13073-019-0650-x.

16. Marri PR, Bannantine JP, Golding GB. Comparative genomics of metabolic pathways in Mycobacterium species: Gene duplication, gene decay and lateral gene transfer. FEMS Microbiol Rev. 2006; Rev 30(2006):906-925.

17. Smith I. Mycobacterium tuberculosis pathogenesis and molecular determinants of virulence. Clin Microbiol Rev. 2003;16(3):463-96. https://doi. org/10.1128/CMR.16.3.463-496.2003.

18. Petkau A, Stuart-Edwards M, Stothard P, van Domselaar G. Interactive microbial genome visualization with GView. Bioinformatics. 2010;26(24): 3125-6. https://doi.org/10.1093/bioinformatics/bta588.

19. Grant JR, Stothard P. The CGView Server: a comparative genomics tool for circular genomes. Nucleic Acids Res. 2008;36(Web Server issue):181-184.

20. Vernikos GS, Parkhill J. Interpolated variable order motifs for identification of horizontally acquired DNA: revisiting the Salmonella pathogenicity islands. Bioinformatics. 2006;22(18):2196-203. https://doi.org/10.1093/bioinformatics/ btl369.

21. Waack S, Keller O, Asper R, Brodag T, Damm C, Fricke WF, et al. Score-based prediction of genomic islands in prokaryotic genomes using hidden Markov models. BMC Bioinformatics. 2006;7(142):1-12.

22. WHO. Multidrug-resistant Tuberculosis (MDR-TB) 2018 Update. 2018.

23. WHO. Treatment of Tuberculosis Guidelines. Fourth Edi. Switzerland; 2010. $1-160$.

24. Wang Y, Zhang S, Li F, Zhou Y, Zhang Y, Wang Z, et al. Therapeutic target database 2020: enriched resource for facilitating research and early development of targeted therapeutics. Nucleic Acids Res. 2020;48(D1): D1031-41. https://doi.org/10.1093/nar/gkz981.

25. Koch A, Cox H, Mizrahi V. Drug-resistant tuberculosis: challenges and opportunities for diagnosis and treatment. Curr Opin Pharmacol. 2018;42:715. Available from: https://doi.org/10.1016/j.coph.2018.05.013, 2018.

26. Pang Y, Lu J, Wang Y, Song Y. ... SW-A agents, 2013 U. study of the rifampin monoresistance mechanism in Mycobacterium tuberculosis. Am Soc Microbiol. 2013;57(2):893-900. Available from: https://aac.asm.org/content/ 57/2/893.short. https://doi.org/10.1128/AAC.01024-12.

27. Zhang Y, Yew W-W. Mechanisms of drug resistance in Mycobacterium tuberculosis: update 2015. Int J Tuberc Lung Dis. 2015;19(11):1276-89. https://doi.org/10.5588/jijld.15.0389.

28. WHO. The use of molecular line probe assays for the detection of resistance to second-line anti-tuberculosis drugs. Geneva: WHO; 2016. 1-40.

29. Rendon A, Tiberi S, Scardigli A, D'Ambrosio L, Centis R, Caminero JA, et al. Classification of drugs to treat multidrug-resistant tuberculosis (MDR-TB): evidence and perspectives. J Thorac Dis. 2016;8(10):2666-71. https://doi. org/10.21037/jtd.2016.10.14.

30. Besser J, Carleton HA, Lindsey RL, Trees E. Next-generation sequencing technologies and their application to the study and control of bacterial infections. Clin Microbiol Infect. 2018;24(4):335-41. https://doi.org/10.1016/j. cmi.2017.10.013.

31. Maaruf M, Zakihalani M, Halim A, Izwan M, Lian L, Nazalan M, et al. Genomics data genome sequencing and annotation of Mycobacterium tuberculosis. GDATA. 2016;7:119-20. https://doi.org/10.1016/j.gdata.2015.12. 030.

32. Han SJ, Song T, Cho YJ, Kim JS, Choi SY, Bang HE, et al. Complete genome sequence of Mycobacterium tuberculosis $\mathrm{K}$ from a Korean high school outbreak, belonging to the Beijing family. Stand Genomic Sci. 2015;10(1):18. https://doi.org/10.1186/s40793-015-0071-4.

33. Behra PRK, Pettersson BMF, Ramesh M, Dasgupta S, Kirsebom LA. Insight into the biology of Mycobacterium mucogenicum and Mycobacterium neoaurum clade members. Sci Rep. 2019;9(1):7-12. https://doi.org/10.1038/ s41598-019-55464-5.

34. Parish T, Stoker NG. The common aromatic amino acid biosynthesis pathway is essential in Mycobacterium tuberculosis. Microbiology. 2002; 148(10):3069-77. https://doi.org/10.1099/00221287-148-10-3069.

35. Parra M, Stahl S, Hellmann H. Vitamin B6 and its role in cell metabolism and physiology. Cells. 2018;7(7):84. https://doi.org/10.3390/cells7070084.

36. Shea J, Halse TA, Lapierre P, Shudt M, Kohlerschmidt D, Van Roey P, et al. Comprehensive whole-genome sequencing and reporting of drug resistance profiles on clinical cases of Mycobacterium tuberculosis in New York. J Clin Microbiol. 2017;55(6):1871-82. https://doi.org/10.1128/JCM.002 98-17.

37. Phelan J, Sullivan DMO, Machado D, Ramos J, Whale AS, Grady JO, et al. The variability and reproducibility of whole genome sequencing technology for detecting resistance to anti-tuberculous drugs. Genome Med. 2016:8(132):19. https://doi.org/10.1186/s13073-016-0385-x.

38. Maladan Y, Krismawati H, Oktavian A, Lestari CSW. Improving multidrugresistance tuberculosis Papua's management using whole genome sequencing. In: Advances in Health Sciences Research; 2020. p. 1-7

39. Ssengooba W, Meehan CJ, Lukoye D, William G, Musisi K, Joloba ML, et al. Infection, genetics and evolution whole genome sequencing to complement tuberculosis drug resistance surveys in Uganda. Infect Genet Evol. 2016;40:8-16. https://doi.org/10.1016/j.meegid.2016.02.019.

40. Zaczek A, Brzostek A, Augustynowicz-Kopec E, Zwolska Z, Dziadek J, et al. Genetic evaluation of relationship between mutations in $r p o B$ and resistance of Mycobacterium tuberculosis to rifampin. BMC Microbiol. 2009: 9(1):1-8. https://doi.org/10.1186/1471-2180-9-10.

41. Ramaswamy SV, Reich R, Dou SJ, Jasperse L, Pan X, Wanger A, et al. Single nucleotide polymorphisms in genes associated with isoniazid resistance in Mycobacterium tuberculosis. Antimicrob Agents Chemother. 2003;47(4):124150. https://doi.org/10.1128/AAC.47.4.1241-1250.2003.

42. Hameed HMA, Islam MM, Chhotaray C, Wang C, Liu Y, Tan Y, et al. Molecular targets related drug resistance mechanisms in MDR-, XDR-, and TDR-Mycobacterium tuberculosis strains. Front Cell Infect Microbiol. 2018;8. https://doi.org/10.3389/fcimb.2018.00114.

43. Operario DJ, Koeppel AF, Turner SD, Bao Y, Pholwat S, Banu S, et al. Prevalence and extent of heteroresistance by next generation sequencing of multidrug- resistant tuberculosis. PLoS One. 2017;12(7):1-14. https://doi. org/10.1371/journal.pone.0181284.

44. Maningi NE, Daum LT, Rodriguez JD, Mphahlele M, Peters RPH, Fischer GW, et al. Improved detection by next-generation sequencing of pyrazinamide resistance in Mycobacterium tuberculosis isolates. J Clin Microbiol. 2015; 53(12):3779-83. https://doi.org/10.1128/JCM.01179-15.

45. Goig GA, Cancino-Muñoz I, Torres-Puente M, Villamayor LM, Navarro D, Borrás R, et al. Whole-genome sequencing of Mycobacterium tuberculosis directly from clinical samples for high-resolution genomic epidemiology and drug resistance surveillance: an observational study. The Lancet Microbe. 2020;1 (4):e175-83. https://doi.org/10.1016/S2666-5247(20)30060-4.

46. Illumina. Nextera ${ }^{\circledR}$ XT Library Prep Reference Guide. Illumina. 2016. 1-28 p.

47. Illumina. MiSeq System Denature and Dilute Libraries Guide. 2017.

48. Kapopoulou A, Lew JM, Cole ST. The MycoBrowser portal: a comprehensive and manually annotated resource for mycobacterial genomes. Tuberculosis. 2011;91(2011):8-13. https://doi.org/10.1016/j.tube.2010.09.006.

\section{Publisher's Note}

Springer Nature remains neutral with regard to jurisdictional claims in published maps and institutional affiliations.

\section{Ready to submit your research? Choose BMC and benefit from:}

- fast, convenient online submission

- thorough peer review by experienced researchers in your field

- rapid publication on acceptance

- support for research data, including large and complex data types

- gold Open Access which fosters wider collaboration and increased citations

- maximum visibility for your research: over $100 \mathrm{M}$ website views per year

At $\mathrm{BMC}$, research is always in progress.

Learn more biomedcentral.com/submission 